\title{
Effects of melatonin on protecting against lung injury (Review)
}

\author{
WEIWEI WANG and JU GAO \\ Department of Anesthesiology, Clinical Medical College of Yangzhou University, Northern Jiangsu
People's Hospital Affiliated to Yangzhou University, Yangzhou, Jiangsu 225001, P.R. China
}

Received March 13, 2020; Accepted August 21, 2020

DOI: $10.3892 /$ etm.2021.9659

\begin{abstract}
Melatonin (MT; N-acetyl-5-methoxy-tryptamine), which has multiple effects and roles, is secreted from the pineal gland at night according to the daily rhythm. In addition to circadian regulation, MT has anti-inflammatory, antioxidant and anticancer functions. Recent studies postulated that MT serves a critical role in apoptosis, anti-ischemic reperfusion injury and anti-proliferative effects on various cells. The current review reported on the underlying mechanism behind the protective effect of MT on lung diseases, such as acute lung injury, acute respiratory distress syndrome, chronic obstructive pulmonary disease, lung ischemia-reperfusion injury, sepsis-induced lung injury and ventilator-induced lung injury. MT is considered an adjuvant with therapeutic drugs for preventing inflammation and is responsible for regulating patient sleep cycles in the intensive care unit. The current review described the anti-inflammatory and antioxidant efficiency of MT with a focus on the molecular mechanisms of action in various lung injuries.
\end{abstract}

\section{Contents}

1. Introduction

2. Anti-inflammatory effect of MT

3. Antioxidant effect of MT

4. Immune system regulation of MT

5. MT and ALI

6. MT and LIRI

7. MT and asthma

8. MT and COPD

9. MT and VILI

10. Conclusion

Correspondence to: Professor Ju Gao, Department of Anesthesiology, Clinical Medical College of Yangzhou University, Northern Jiangsu People's Hospital Affiliated to Yangzhou University, 98 Nan Tong Western Road, Yangzhou, Jiangsu 225001, P.R. China E-mail: doctor2227@163.com

Key words: melatonin, acute lung injury, ventilator-induced lung injury, chronic obstructive pulmonary disease

\section{Introduction}

Lung diseases are major health issue and leading cause of death worldwide (1). The lungs are an essential organ for exchanging blood and oxygen and are one of the most vulnerable organs in the human body. Lung diseases include various abnormalities that affect the pulmonary stroma and alveoli, including acute lung injury (ALI), asthma, chronic obstructive pulmonary disease (COPD), cancer, ventilator-induced lung injury (VILI) and X-ray radiation-induced lung injury (2). For instance, ALI is a severe health problem in certain developing countries such as India, accounting for $30 \%$ of all deaths in children under 5 years of age (3). Additionally, COPD frequently occurs in the elderly population due to infection, smoking, chemicals and air pollution and has high morbidity and mortality worldwide (4). Lung cancer is a malignancy with the fastest growth of morbidity and mortality and is one of the greatest threats to human health worldwide (5). Asthma is characterized by breathing difficulty and shortness of breath, wheezing, coughing and nocturnal activity and is a common airway inflammatory disorder. VILI is a common complication induced by mechanical ventilation in the intensive care unit (ICU) and perioperative period (6).

Melatonin (MT) is a hormone produced by the pineal gland, which is superior to the third ventricle of the brain (7). MT has the ability to diffuse in and out of cells due to its chemical structure and low molecular weight (8). MT is synthesized by the pineal gland, in the bone marrow, the eyes and the gastrointestinal tract. The synthesis of MT arises from 5-hydroxytryptamine and the rate-limiting enzyme in this reaction is MT-N-acetyltransferase (9). Certain researchers have indicated that MT can lighten mottled skin by downregulating melanophores $(10,11)$

Moreover, MT regulates the human chronobiological function known as the circadian rhythm (12). The suprachiasmatic nuclei (SCN) located in the hypothalamus are responsible for maintaining the circadian rhythm in mammals (13). Sleep state and metabolism are activated by MT, which is stimulated by the SCN (14). In the human 24-h sleeping cycle, MT secretion changes periodically based on an internal biological clock (15). Apart from the central circadian clock, MT also modulates peripheral tissues and organs, making MT the best marker of the circadian rhythm (16). Generally, MT secretion is highest between 11:00 p.m. and 2:00 a.m., and the secretion decreases sharply after 7:00 a.m (17). Additionally, the level of MT is affected by light intensity, age and other factors $(18,19)$. 
Notably, light during the night can severely disrupt MT production and Circadian rhythms of patients in ICU in hospitals (20). MT administration and its receptor agonists have advantages in preventing delirium by promoting nocturnal sleep $(21,22)$.

MT has three receptors: MT receptor-1 (MT1), MT2 and MT3. MT1 and MT2 are G protein-coupled receptors, which are involved in various cell signal transduction processes, such as the regulation of the immune system and photosensitivity (23). Additionally, MT1 receptors are located in the locus coeruleus and lateral hypothalamus (rapid eye movement area), while MT2 receptors are located in the reticular thalamus (non-rapid eye movement area) in selective MT1/MT2 receptor ligands and MT1/MT2 receptor knockout mice (23). Thus, MT1 is considered to establish and maintain the circadian rhythm, mood, pain and sleep (24). Recently, certain researchers have demonstrated that the structure of MT2 allowed for accurate mapping of type 2 diabetes-related single-nucleotide polymorphisms $(23,25,26)$. MT1, rather than MT2, has been implicated in circadian rhythm regulation. It has been reported that MT1 receptors are involved in Alzheimer's and Huntington's diseases, and patients with depression (26). Moreover, the expression level of MT1 and MT2 decreased as the cancer stage increased and MT2 was an independent prognostic factor for survival rate in patients with NSCLC (27). Additionally, MT has an affinity for specific MT membrane receptors, including retinoic acid receptor-related orphan nuclear receptors (RORs) (28). The MT-ROR $\alpha$ axis serves as a novel endogenous protective signalling pathway in the vasculature, regulates intraplaque inflammation and stabilizes rupture-prone vulnerable plaques (29).

The summary was designed to critically review scientific studies that demonstrate the therapeutic actions of melatonin on lung injury. The molecular aspects of melatonin's therapeutic potential is also discussed with due reference to molecular targets and pharmacological effects.

\section{Anti-inflammatory effect of MT}

The inflammation mechanism is a natural human response to bodily injury from injection or chemical and physical stimulation. Inflammatory cells (such as leukocytes, macrophages, mast cells and endothelial cells), which release TNF- $\alpha$, IL-1 $\beta$ and IL-6, are involved in the process of inflammatory tissue repair (30). Inhibition of the inflammatory process is one of the essential strategies in antagonizing chronic or acute inflammatory diseases, including pneumonia, asthma and COPD (30-33). Anti-inflammatory actions by MT are of particular clinical significance in high-grade inflammation, such as sepsis-induced lung injury, ischemia-reperfusion lung injury and brain injury (34). Following tissue damage, MT activates pro-inflammatory cytokines and other mediators (35). Additionally, MT administration suppresses inflammatory processes, including nitric oxide (NO) release, activation of cyclooxygenase-2, nucleotide-binding oligomerization domain-like receptor protein 3 (NLRP3) inflammasome, toll-like receptor 4 (TLR-4) and mTOR signalling, and amyloid- $\beta$ toxicity (36-39). Additionally, previous studies proved that exogenous MT attenuated the inflammatory response by increasing the expression of silent information regulator 1 (SIRT1) activity, which exerts anti-inflammatory effects $(34,40)$.
Furthermore, the mechanisms contributing to inflammatory effects are oxidative stress and oxidative-mediated processes such as oxygen free radical reaction and lipid peroxidation (41). Inflammatory cells secrete numerous cytokines and chemokines including IL-1 $\beta$, TNF- $\alpha$, MCP-1, which are responsible for the production of reactive oxygen species (ROS) in phagocytic cells at the beginning of the inflammation phase (42). ROS adversely impact the action of neutrophils and macrophages, and decrease the activation of apoptotic signals (43).

Concerning anti-inflammatory and molecular mechanisms, various novel perspectives focus on the immune-pineal axis, which serves as a negative feedback mechanism to mediate the immune system (44). Moreover, these pro-inflammatory cytokines including TNF- $\alpha$, IL- $1 \beta$ and IL- 6 have several detrimental effects on individual tissues, including lung, liver and kidney, and manifest as endothelial cell damage, vascular permeability changes, tissue degeneration and edema $(45,46)$.

\section{Antioxidant effect of MT}

MT serves as an antioxidant and rapidly disappears from the blood and in the systemic circulation of mammals, once they are under conditions of high oxidative stress (47). MT acts as an antioxidant either directly or indirectly via the MT receptors MT1 and MT2 (27). Novel research has indicated that MT depleted ROS and increased glutathione (GSH) levels to inhibit the development of lung cancer (48). This result indicates that the unique indole composition has a leading role in the antioxidant effect of MT due to its high stability and electroactivity (49).

Moreover, MT O-methyl and N-acetyl residues are the basis of its amphiphilicity, allowing the molecule to enter all organs and subcellular compartments, and are the primary facilitators of its antioxidant properties (50). A recent study reported that MT significantly improved the tolerance of apple seedlings to waterlogging stress as ROS are hypothesized to serve a critical role in the response of the plant to waterlogging pressure (51). MT administration increased ascorbic acid levels and the activity of antioxidants, including superoxide dismutase (SOD), catalase (CAT) and peroxidase in rats (52). Numerous in vitro and in vivo studies have demonstrated that exogenous MT suppresses oxidative stress $(53,54)$. Another study reported that MT-loaded lipid-core nanocapsules (Mel-LNC) increased the fluorescence intensity of Caenorhabditis elegans that encodes the antioxidant enzyme SOD-3 to inhibit lipid peroxidation (54). Treatment with MT following $\mathrm{CCl}_{4}$ exposure in rats resulted in a significant increase in the activity of lung tissue oxidized proteins, including myeloperoxidase (MPO) and malondialdehyde (MDA) (55). Additionally, the same author indicated that MT upregulated the levels of intracellular antioxidant enzymes, including SOD2 and glutathione peroxidase 1 (56).

There is a plethora of clinical treatments targeting the significant therapeutic role of MT against different diseases, including lung disease, liver disease, kidney disease, diabetes, Alzheimer's disease and Parkinson's disease $(46,57,58)$. A randomized, double-blinded, placebo-controlled trial indicated that MT supplementation ( $2 \times 5 \mathrm{mg} /$ day for 12 weeks) significantly reduces the sum of total antioxidant capacity, including 


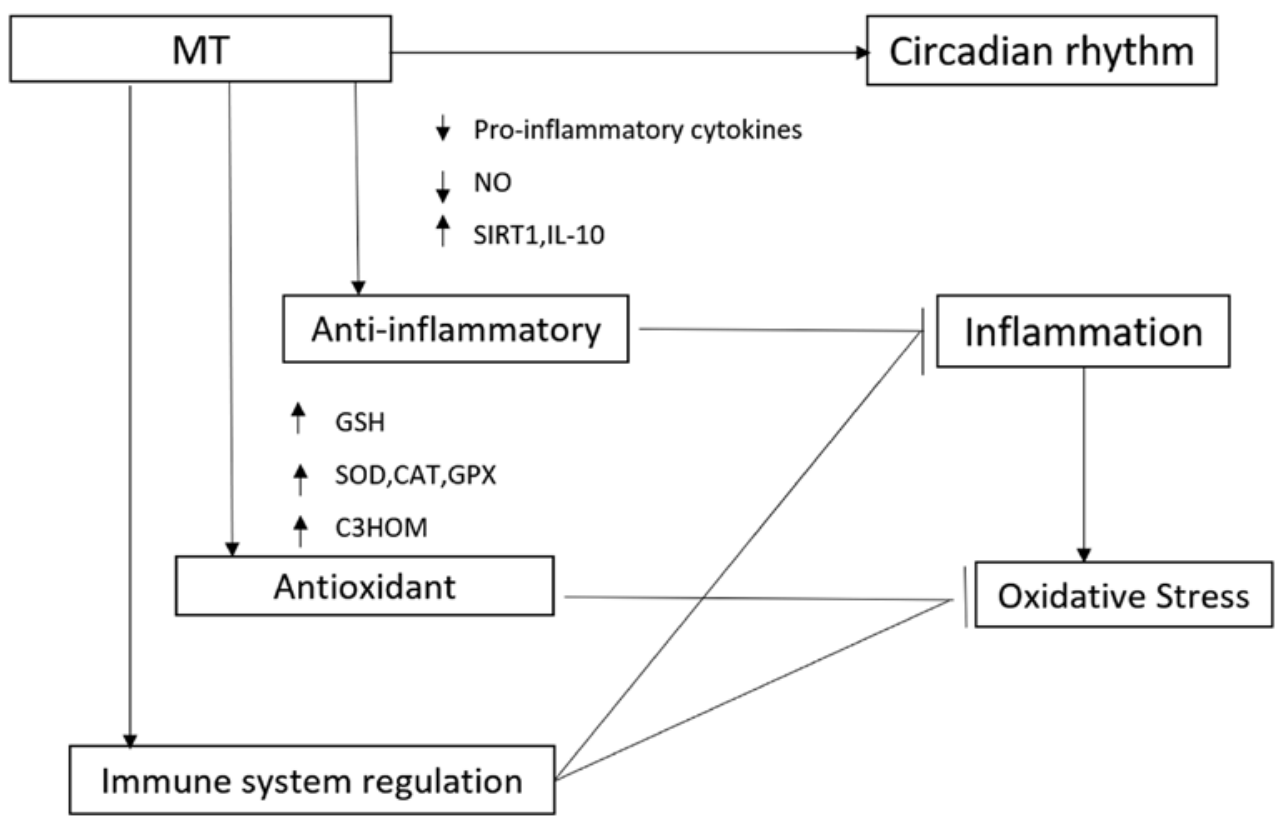

Figure 1. Schematic representation of the mechanisms of action of MT in the treatment of respiratory disorders. MT, melatonin; NO, nitric oxide; SIRT1, silent information regulator 1; IL-10, interleukin 10; GSH, glutathione; SOD, superoxide dismutase; C3HOM, cyclic 3-hydroxyMT.

GSH and MDA, in patients with diabetic hemodialysis (59). MT administration substantially minimized oxidative stress and directly acted on its membrane receptors MT1 and MT2, which serve a vital role during the whole gestational period in humans and animals (60). A previous study indicated that cyclic 3-hydroxy-MT is a product that includes antioxidative effects of MT and mediates its metabolite interaction with ROS (61). Another study demonstrated that administering a subcutaneous implant containing $18 \mathrm{mg}$ of MT with lamb model and ovine prepubertal cumulus cells, promoted antioxidant capacity (SOD1, Glutathione peroxidase 4 and CAT) via ROR $\alpha$ in ovine prepubertal cumulus cells (62).

\section{Immune system regulation of MT}

The regulatory effect of MT in the immune system is not surprising, as a correlation has been demonstrated between melatonin production and circadian in immune function, pinealectomy has been shown to cause changes in the immune system, and in vivo and in vitro administration of melatonin has been shown to cause changes in immune functions (Fig. 1) (63). The immune system is notably complex, which becomes evident with the multitude of participating cell types and subtypes, as well as humoral factors, the flexible regulatory network, the participation of non-immune cells in the classic sense and in the short- and long-term temporal changes (64). With regard to acute inflammation, the immune system activates the required cellular and humoral processes, later actively terminating them and initiating healing (65).

Coronaviruses (CoVs) are RNA viruses that infect both humans and animals. Infection involves the respiratory, gastrointestinal and central nervous systems. Since the outbreak of COVID-19 at the end of 2019, thousands of people have been infected or succumbed to the disease (66). Unfortunately, there is a lack of a specific treatment for COVID-19. In Severe Acute Respiratory Syndrome-CoV- and Middle East Respiratory
Syndrome-CoV-infected animal models, marked inflammatory and immune responses activate a 'cytokine storm' and the apoptosis of epithelial cells and endothelial cells; subsequently, vascular leakage and abnormal $\mathrm{T}$ cell and macrophage responses ensue and induce ALI/acute respiratory distress syndrome (ARDS) or even death (67). Melatonin is effective in critical care patients by reducing vessel permeability, anxiety, sedation use, and improving sleeping quality, which might also be beneficial for better clinical outcomes for COVID-19 patients (66).

MT can be classified as an immune stimulatory agent. Notably, the effect of anti-inflammatory actions has been observed in cells in the blood or other body fluids (68). Previous tudies have indicated that MT administration had positive effects in alleviating ARDS-induced by viruses, bacteria and radiation $(37,69)$. MT exerts regulatory actions on the immune system and directly enhances the immune response by increasing the proliferation and maturation of natural killing cells, T and B lymphocytes, granulocytes and monocytes in the bone marrow and other tissues (70).

\section{MT and ALI}

ALI is a common clinical respiratory disease that often develops into a more complex syndrome termed ARDS (71). It has multiple etiologies and often results in severe respiratory failure and death (72). According to the World Health Organization (WHO), ARDS was the leading cause of death in Intensive Care Units from 50 Countries in 2014 (73). Annually, $\sim 2$ million days in ICU and 75,000 deaths occur in the USA due to ARDS (74). The 'Berlin definition' was developed in 2012 based on the clinical standards for ALI/ARDS (75). Therefore, preventing ARDS and its complications is an urgent clinical problem for doctors. A high number of clinical and experimental studies were dedicated to prevention and diagnosis in order to improve the prognosis of ARDS. 
Table I. Studies investigating the effect of melatonin on lung injury.

\begin{tabular}{|c|c|c|c|c|}
\hline First author (year) & Studied model & Disease & Main findings & Refs. \\
\hline Campos (2004) & Human & Asthma & Significantly improve sleep quality & $(98)$ \\
\hline Ozdinc (2016) & Rat & Acute lung injury & $\begin{array}{l}\text { inhibits neutrophil movement and adhesion, } \\
\text { decreases edema, neutrophil infiltration in } \\
\text { experimental rats induced lung injury }\end{array}$ & $(75)$ \\
\hline Chiu (2012) & Rat & $\begin{array}{l}\text { Lung ischemia- } \\
\text { reperfusion injury }\end{array}$ & $\begin{array}{l}\text { Diminish the pulmonary microvascular } \\
\text { permeability and attenuate lipid peroxidation }\end{array}$ & $(46)$ \\
\hline Wang (2004) & Rat & Asthma & $\begin{array}{l}\text { Inhibits the expression of NF- } \kappa \beta \text { and downregulates } \\
\text { the inducible NO synthesis activity }\end{array}$ & (93) \\
\hline He (2019) & Rat & $\begin{array}{l}\text { Chronic obstructive } \\
\text { pulmonary disease }\end{array}$ & $\begin{array}{l}\text { Suppresses apoptosis and endoplasmic } \\
\text { reticulum stress and increases the expression } \\
\text { of silent information regulator } 1\end{array}$ & $(102)$ \\
\hline $\begin{array}{l}\text { Pedreira (2008), } \\
\text { Gu (2015) }\end{array}$ & Rat & $\begin{array}{l}\text { Ventilator-induced } \\
\text { lung injury }\end{array}$ & $\begin{array}{l}\text { Increasing the anti-inflammatory (IL-10) } \\
\text { response and stabilizing cytoskeleton structure } \\
\text { and the activation of target genes }\end{array}$ & $(6,112)$ \\
\hline
\end{tabular}

Ozdinc et al (75) reported that MT improved the histopathology of pulmonary contusion and distant organs, including the liver and kidney, by diminishing oxidative stress, including decreasing the levels of ROS, MDA and total antioxidant capacity. Moreover, their findings demonstrated that MT has a significant antioxidant effect on contused lungs within $24 \mathrm{~h}$. Additionally, MT inhibited neutrophil movement and adhesion, and decreased edema and neutrophil infiltration in an experimental model of rat lung injury. Dong et al (45) examined the molecular mechanisms of the inhibitory effect of MT against lipopolysaccharide (LPS)-induced ALI in Sprague-Dawley rats via examination of the inhibition of p38 MAPK overactivation. The results demonstrated that downstream receptors, as well as nuclear factor- $\kappa \beta(\mathrm{NF}-\kappa \mathrm{B})$ and other pro-inflammatory cytokines, were decreased due to the inhibition of the p38 MAPK signaling pathway activity. Additionally, Zhang et al (76) indicated that MT exerts a protective effect on lung tissues during ALI, including the p38 MAPK signalling pathway, with decreased expression of P-selectin, intercellular adhesion molecule-1 and NF- $\mathrm{B}$ (Table I). Moreover, MT administration inhibited the activation of the NLRP3 inflammasome via suppressing the release of extracellular histones and directly blocking histones to reduce pulmonary injury in an LPS-induced ALI mouse model (35).

Taslidere et al (77) revealed that fibrosis, interstitial hemorrhage, epithelial desquamation in bronchioles and alveoli, intra-alveolar edema, and leukocyte and macrophage infiltration were reduced in the MT+CCL4 group compared with the CCL4 group. Furthermore, the results demonstrated that the MDA level of the control group was significantly higher compared with the treatment group. Nevertheless, antioxidant factors, including GSH and CAT levels, were markedly lower compared with the treatment group. Wu et al (78) studied the promising role of intravenous administration of MT at $5 \mathrm{mg} / \mathrm{kg}$ in a murine heat stroke model. The results reported that MT significantly prolonged the survival time of rats in the heat stroke group and attenuated heat stroke-induced hyperthermia and hypotension. In these studies, MT served as an antioxidant drug to protect lung tissue, which was damaged by various factors. Additionally, it has been reported that ALI is associated with an increase in the levels of different pro-inflammatory cytokines and chemokines, including interleukin (IL)-6, IL-22 and TNF $\alpha$, in lung tissues (79).

\section{MT and LIRI}

Lung ischaemia-reperfusion injury (LIRI), known as a frequent and severe clinical complication, has a high mortality after lung transplantation worldwide $(80,81)$. LIRI is a pathological process with the clinical feature of initial restriction of blood supply to lung organs followed by the restoration of perfusion, which involves oxidative stress (82). The primary cause of this may be the imbalance of excessive oxygen free radical production and insufficient antioxidant mechanisms (83). Ischemia/reperfusion (IR) injury is a severe clinical event that may induce tissue injury, whose primary underlying mechanisms include an inflammatory immune response, the release of inflammatory mediators and the induction of apoptosis (84).

Chiu et al (46) used MT pretreatment $(15 \mathrm{mg} / \mathrm{kg}$ intraperitoneally) $15 \mathrm{~min}$ prior to liver IR to compare the changes in inflammatory factors prior to and following the operation. The results demonstrated that MT pretreatment prior to liver IR significantly diminished pulmonary microvascular permeability and attenuated lipid peroxidation in the lungs. Additionally, another study reported that intravenous administration of MT $(10 \mathrm{mg} / \mathrm{kg})$ significantly inhibited the expression of NF- $\kappa \beta$ and downregulated nuclear factor erythroid-2-related factor 2 synthesis activity in hepatic IR-induced lung injury (63). Furthermore, the results determined that the underlying mechanism of the MT effect on IR-induced lung injury was the inhibition of the activation of the JNK/p38 signalling pathway. Takhtfooladi et al (84) reported that MT pretreatment 
(10 mg/kg intravenously) significantly improved lung tissue injury of skeletal muscle IR in rats. These results indicate that lung tissues exhibit less severe histological abnormalities, including neutrophilic infiltration, intra-alveolar hemorrhage and edema, compared with the IR group. Moreover, lung tissue MPO activity and NO levels were significantly decreased by IR following MT pretreatment.

\section{MT and asthma}

Asthma has a high occurrence and is the most common long-term inflammatory syndrome (85). It affects the lower airway mucosa by producing IL-4, IL-13, IL-5 and IL-9 (86). The typical clinical manifestations including wheezing, breathlessness, coughing and difficulty breathing, particularly at night or in the early morning (65). Certain researchers have indicated that asthma, as a chronic inflammatory disorder of the airways, is associated with numerous cells and cellular elements, including mast cells, eosinophils, type $2 \mathrm{~T}$ helper cells, macrophages, neutrophils and epithelial cells $(87,88)$. In asthma, type $2 \mathrm{~T}$ helper cells have a crucial role in producing inflammatory cytokines, such as IL-4, IL-9, IL-10 and IL-13 (89). Additionally, oxidative stress is another essential factor in stimulating inflammatory responses in asthma (90). According to WHO reports, in developed countries asthma affects $10 \%$ of the population and people with asthma have an increased risk of developing anxiety disorders (91). Although the treatment strategies of asthma are diverse in developing countries, its prevalence is still rapidly increasing yearly (92). Wang et al (93) demonstrated that MT administration $(10 \mathrm{mg} / \mathrm{kg}$ ) significantly inhibited the expression of $\mathrm{NF}-\kappa \beta$ and downregulated inducible NO synthase activity in lung tissues and substantially reduced NO production in bronchoalveolar lavage fluid (BALF) in a rat model of asthma.

Researchers have reported that TLR-9 is one of the most extensively studied TLRs used to treat asthma. Wu et al (94) reported that, compared with wild-type (WT) mice, MT effectively inhibited airway inflammation in an asthmatic mouse model induced by ovalbumin (OVA). Additionally, the experimental results indicated that the protein expression of immunoglobulin E (IgE) and MT levels in serum and BALF were reduced in OVA-induced WT mice; however, TLR9(-/-) mice significantly restored these decreases. SP600125, a JNK-specific inhibitor, significantly deceased OVA-induced expression of TLR9 and reset the level of MT in OVA-treated WT mice. In summary, the JNK-TLR9 signalling pathway mediated the airway inflammation process via inhibiting MT biosynthesis. Furthermore, Shin et al (95) reported that intraperitoneal injection of MT (10 or $15 \mathrm{mg} / \mathrm{kg}$ daily) significantly decreased the numbers of inflammatory cells, airway inflammation, and IgE, IL-4, IL-5 and IL-13 expression levels in an OVA-induced allergic asthma rat model. In vitro experiments indicated that pro-inflammatory cytokine expression and matrix metalloproteinase-9 activity were significantly suppressed by MT administration in TNF- $\alpha$-stimulated BEAS- $2 B$ cells Further research by the same authors revealed that MT notably suppressed chronic airway inflammation, accompanied by a reduction in the expression levels of mucin 5AC (MUC5AC) mRNA and protein (33). In an in vitro experiment, MT treatment suppressed IL-6 production and MUC5AC expression in EGF-stimulated H292 cells. The authors concluded that MT significantly inhibited the expression of MUC5AC via the downregulation of the MAPK signalling pathway in an OVA-induced asthma murine model (96). A double-blinded, randomized, placebo-controlled clinical research trial included MT treatment ( $3 \mathrm{mg} /$ day) or placebo for 4 weeks in 22 women with asthma and the Pittsburgh Sleep Quality Index, Epworth Sleepiness Scale (97) and pulmonary function were assessed (98). The results indicated that MT significantly improved sleep quality in patients with asthma in comparison with the placebo group.

\section{MT and COPD}

COPD is a devastating lung disease that affects alveolar structures and adversely impacts ventilation (99). Exposure to cigarette smoke is considered to be the leading risk factor for COPD, as well as air pollution and infection. Currently, COPD is a well-known lung disease and an increasing global health problem (100). The main pathological feature of COPD is chronic airway inflammation and an abnormal response to the external environment, resulting in small airway and alveolar restructuring, as reflected by a lack of ventilation function and emphysema in COPD (101).

He et al (102) observed the mechanism of MT in a rat model of COPD established using cigarette smoke with LPS. They reported that MT administration significantly suppressed apoptosis and endoplasmic reticulum stress, and significantly increased the expression of SIRT1 in lung tissues. Furthermore, the results demonstrated that inhibition of SIRT1 using EX527 reversed the beneficial effects of MT administration against apoptosis. Additionally, another study indicated that MT reduced the inflammatory mediators in cigarette smoke (CS) exposed mice and CS condensate-treated J774 macrophages, which were associated with enhanced SIRT1 expression induced by MT (103). These results indicated that MT serves as a SIRT1 enhancer and may be have potential as an active therapeutic agent to control CS-induced airway inflammation.

\section{MT and VILI}

Mechanical ventilation is increasingly used in life support and routine anesthesia; however, VILI has always represented a challenging issue (104). Mechanical ventilation translates into prolonged hospital stays, increased burden on the health care system and increased treatment costs (105). The mechanisms responsible for VILI are complex. Increased tidal volumes cause the lung tissues to stretch, which is potentially problematic, as it induces a local cytokine storm which is known to initiate VILI (106). A previous study reported that obese patients may suffer fatal emphysema with high airway pressure and postoperative pulmonary complications following intraoperative ventilation (107). However, a previous study revealed that obesity served a protective role in VILI by alleviating pulmonary endothelial barrier injury and the inflammatory response (108). A previous study reported that MT administration significantly decreased VILI by increasing the anti-inflammatory response (IL-10) despite an unexpected increase in oxidative stress (6). However, the specific mechanism underlying MT and VILI has not been elucidated. 
Although the therapeutic role of MT for the clinical treatment of VILI has not been assessed until now, it can be hypothesized. Recently, protective lung ventilation strategies have beneficial effects against VILI, including optimizing mechanical ventilation by setting suitable positive end-expiratory pressure, low tidal volume ventilation strategy, recruitment maneuvers and a lax hypercapnia strategy (109). Adherens and tight junctions are essential components in maintaining the integrity of the alveolar epithelial barrier. Rho belongs to the Ras superfamily of low molecular weight GTPases, which have a key role in the formation of the alveolar epithelial cell cytoskeleton, as well as Rho-associated coiled-coil forming protein kinase (110). Sripathi et al (111) reported that MT treatment could be beneficial in protecting mitochondria under oxidative stress and maintaining the structure of the cytoskeleton in the retinal pigment epithelium. Moreover, p120 serves as an essential protein in the regulation of cell junctions and protects against VILI by regulating both adherens and tight junctions by reducing the degradation of occludin via the inhibition of RhoA activity (112). Finally, the effect of MT on stabilizing cytoskeleton structure and the activation of target genes may represent a novel way to alleviate VILI.

\section{Conclusion}

Treatment with MT has been demonstrated to exert positive effects on the alleviation of the aforementioned lung injuries, including ALI/ARDS, LIRI, asthma, COPD and VILI. At a molecular level, MT reduces lung injury via antioxidative effects and upregulation of anti-inflammatory cytokines, profibrotic cytokines and chemokines in lung tissues, which have a pivotal role in the pathophysiology of lung injury.

In ALI/ARDS, MT serves as a crucial antioxidant and anti-inflammatory vehicle that has vital roles in the alleviation of oxidative stress and the excessive production of pro-inflammatory cytokines and chemokines in lung tissues. In LIRI, MT inhibits the activation of the JNK/p38 signalling pathway to protect against lung injury. Additionally, MT decreases the expression of MPO and NO in lung tissues. In asthma, MT improves lung function by alleviating airway inflammation and reducing the release of inflammatory cytokines via the downregulation of NF- $\mathrm{BB}$. Additionally, it can be hypothesized that MT reduces the severity of chronic asthma via the inhibition of the JNK-TLR9 signalling pathway. It is well known that there is systemic oxidative stress in COPD and antioxidant therapeutic targets are required for the improvement of lung function in patients with COPD (113). Additionally, the critical role of SIRT1 in chronic inflammation cannot be ignored. In VILI, MT reduces the severity of injury via its anti-inflammatory and inhibitory actions on the expression levels of pro-inflammatory cytokines. Notably, recent research has documented the positive effects of MT in treating COVID-19-induced pneumonia and ALI $(66,114)$. Furthermore, the effects of MT on stabilizing cytoskeletal structure and inhibiting the expression of cytoskeletal proteins are areas of interests for the future research of VILI.

\section{Acknowledgements}

Not applicable.

\section{Funding}

The present study was supported by the Yangzhou International Cooperation Project: 'Yangzhou Science and Technology Plan Project' (grant no. YZ2019145).

\section{Availability of data and materials}

Not applicable.

\section{Authors' contributions}

WW reviewed literature and wrote the manuscript. JG reviewed and revised the manuscript. JG gave final approval for publication. Both authors read and approved the final version of the manuscript.

\section{Ethics approval and consent to participate}

Not applicable.

\section{Patient consent for publication}

Not applicable.

\section{Competing interests}

The authors declare that they have no competing interests.

\section{References}

1. Harhay $\mathrm{MO}$ and King $\mathrm{CH}$ : Global burden of disease in young people aged 10-24 years. Lancet 379: 27-28, author reply 28 , 2012.

2. Habtemariam S, Daglia M, Sureda A, Selamoglu Z, Gulhan MF and Nabavi SM: Melatonin and Respiratory Diseases: A Review. Curr Top Med Chem 17: 467-488, 2017.

3. Rudan I, Tomaskovic L, Boschi-Pinto C and Campbell H; WHO Child Health Epidemiology Reference Group: Global estimate of the incidence of clinical pneumonia among children under five years of age. Bull World Health Organ 82: 895-903, 2004.

4. Rosenberg SR, Kalhan R and Mannino DM: Epidemiology of Chronic Obstructive Pulmonary Disease: Prevalence, Morbidity, Mortality, and Risk Factors. Semin Respir Crit Care Med 36: 457-469, 2015.

5. Bray F, Ferlay J, Soerjomataram I, Siegel RL, Torre LA and Jemal A: Global cancer statistics 2018: GLOBOCAN estimates of incidence and mortality worldwide for 36 cancers in 185 countries. CA Cancer J Clin 68: 394-424, 2018.

6. Pedreira PR, García-Prieto E, Parra D, Astudillo A, Diaz E, Taboada F and Albaiceta GM: Effects of melatonin in an experimental model of ventilator-induced lung injury. Am J Physiol Lung Cell Mol Physiol 295: L820-L827, 2008.

7. Lerner AB, Case JD, Takahashi Y, Lee TH and Mori W: Isolation of melatonin, the pineal gland factor that lightens melanocytes 1 . J Am Chem Soc 80: 2587, 1958.

8. Lapin V and Ebels I: Effects of some low molecular weight sheep pineal fractions and melatonin on different tumors in rats and mice. Oncology 33: 110-113, 1976.

9. Beñaldo FA, Llanos AJ, Araya-Quijada C, Rojas A Gonzalez-Candia A, Herrera EA, Ebensperger G, Cabello G, Valenzuela GJ and Serón-Ferré M: Effects of Melatonin on the Defense to Acute Hypoxia in Newborn Lambs. Front Endocrinol (Lausanne) 10: 433, 2019.

10. Alvarez-Artime A,Cernuda-Cernuda R,Francisco-Artime-Naveda, Cepas V, Gonzalez-Menendez P, Fernadez-Vega S, Quiros-Gonzalez I, Sainz RM and Mayo JC: Melatonin-Induced Cytoskeleton Reorganization Leads to Inhibition of Melanoma Cancer Cell Proliferation. Int J Mol Sci 21: E548, 2020. 
11. Andersson TPM, Filippini D, Suska A, Johansson TL, Svensson SPS and Lundström I: Frog melanophores cultured on fluorescent microbeads: Biomimic-based biosensing. Biosens Bioelectron 21: 111-120, 2005.

12. Plaimee P, Weerapreeyakul N, Thumanu K, Tanthanuch $\mathrm{W}$ and Barusrux S: Melatonin induces apoptosis through biomolecular changes, in SK-LU-1 human lung adenocarcinoma cells. Cell Prolif 47: 564-577, 2014.

13. Karimfar MH, Rostami S, Haghani K, Bakhtiyari S and Noori-Zadeh A: Melatonin alleviates bleomycin-induced pulmonary fibrosis in mice. J Biol Regul Homeost Agents 29: $327-334,2015$

14. Zisapel N: New perspectives on the role of melatonin in human sleep, circadian rhythms and their regulation. Br J Pharmacol 175: 3190-3199, 2018

15. Genovese T, Di Paola R, Mazzon E, Muià C, Caputi AP and Cuzzocrea S: Melatonin limits lung injury in bleomycin treated mice. J Pineal Res 39: 105-112, 2005.

16. Trivedi AK, Mishra I and Kumar V: Temporal expression of genes coding for aryl-alkamine- $\mathrm{N}$-acetyltransferase and melatonin receptors in circadian clock tissues: Circadian rhythm dependent role of melatonin in seasonal responses. Physiol Behav 207: 167-178, 2019.

17. Kurhaluk $\mathrm{N}$ and Tkachenko $\mathrm{H}$ : Melatonin and alcohol-related disorders. Chronobiol Int 37: 781-803, 2020.

18. Sanchez-Hidalgo M, de la Lastra CA, Carrascosa-Salmoral MP, Naranjo MC, Gomez-Corvera A, Caballero B and Guerrero JM: Age-related changes in melatonin synthesis in rat extrapineal tissues. Exp Gerontol 44: 328-334, 2009.

19. Erren TC and Reiter RJ: Melatonin: A universal time messenger Neuro Endocrinol Lett 36: 187-192, 2015.

20. Bonmati-Carrion MA, Arguelles-Prieto R, Martinez-Madrid MJ, Reiter R, Hardeland R, Rol MA and Madrid JA: Protecting the melatonin rhythm through circadian healthy light exposure. Int J Mol Sci 15: 23448-23500, 2014.

21. Lewis SR, Pritchard MW, Schofield-Robinson OJ, Alderson P and Smith AF: Melatonin for the promotion of sleep in adults in the intensive care unit. Cochrane Database Syst Rev 5: CD012455, 2018

22. Mo Y, Scheer CE and Abdallah GT: Emerging Role of Melatonin and Melatonin Receptor Agonists in Sleep and Delirium in Intensive Care Unit Patients. J Intensive Care Med 31: 451-455, 2016.

23. Gobbi G and Comai S: Differential Function of Melatonin MT1 and MT2Receptors in REM and NREM Sleep. Front Endocrino (Lausanne) 10: 87, 2019.

24. Comai S, Lopez-Canul M, De Gregorio D, Posner A, Ettaoussi M Guarnieri FC and Gobbi G: Melatonin MT1 receptor as a nove target in neuropsychopharmacology: MT1 ligands, pathophysiological and therapeutic implications, and perspectives. Pharmacol Res 144: 343-356, 2019.

25. Owino S, Buonfiglio DDC, Tchio C and Tosini G: Melatonin Signaling a Key Regulator of Glucose Homeostasis and Energy Metabolism. Front Endocrinol (Lausanne) 10: 488, 2019.

26. Hu JJ, Xiao LF, Song LL, Ge WB, Duan HW and Jiang Y: The expression of melatonin receptors MT1 and MT2 is regulated by E2 in sheep oviduct. Gen Comp Endocrinol 286: 113135, 2020.

27. Jablonska K, Nowinska K, Piotrowska A, Partynska A, Katnik E, Pawelczyk K, Glatzel-Plucinska N, Podhorska-Okolow M and Dziegiel P: Prognostic Impact of Melatonin Receptors MT1 and MT2 in Non-Small Cell Lung Cancer (NSCLC). Cancers (Basel) 11: E1001, 2019

28. Xu L, Su Y, Zhao Y, Sheng X, Tong R, Ying X, Gao L, Ji Q, Gao Y, Yan Y, et al: Melatonin differentially regulates pathological and physiological cardiac hypertrophy: Crucial role of circadian nuclear receptor ROR $\alpha$ signaling. J Pineal Res 67: e12579, 2019

29. Ding S, Lin N, Sheng X, Zhao Y, Su Y, Xu L, Tong R, Yan Y, $\mathrm{Fu} \mathrm{Y}$, He J, et al: Melatonin stabilizes rupture-prone vulnerable plaques via regulating macrophage polarization in a nuclear circadian receptor ROR $\alpha$-dependent manner. J Pineal Res 67: e12581, 2019.

30. Puig Á, Rancan L, Paredes SD, Carrasco A, Escames G, Vara E and Tresguerres JAF: Melatonin decreases the expression of inflammation and apoptosis markers in the lung of a senescence-accelerated mice model. Exp Gerontol 75: 1-7, 2016.

31. Peng Z, Zhang W, Qiao J and He B: Melatonin attenuates airway inflammation via SIRT1 dependent inhibition of NLRP3 inflammasome and IL-1 $\beta$ in rats with COPD. Int Immunopharmacol 62 $23-28,2018$.
32. Chen J, Qian C, Duan H, Cao S, Yu X, Li J, Gu C, Yan F, Wang L and Chen G: Melatonin attenuates neurogenic pulmonary edema via the regulation of inflammation and apoptosis after subarachnoid hemorrhage in rats. J Pineal Res 59: 469-477, 2015.

33. Shin I-S, Shin N-R, Park J-W, Jeon C-M, Hong J-M, Kwon O-K, Kim J-S, Lee I-C, Kim J-C, Oh S-R, et al: Melatonin attenuates neutrophil inflammation and mucus secretion in cigarette smoke-induced chronic obstructive pulmonary diseases via the suppression of Erk-Sp1 signaling. J Pineal Res 58: 50-60, 2015.

34. Hardeland R: Melatonin and inflammation-Story of a double-edged blade. J Pineal Res 65: e12525, 2018.

35. Zhang Y, Li X, Grailer JJ, Wang N, Wang M, Yao J, Zhong R, Gao GF, Ward PA, Tan D-X, et al: Melatonin alleviates acute lung injury through inhibiting the NLRP3 inflammasome. J Pineal Res 60: 405-414, 2016.

36. Aguilar SA, Arias PV, Canquil I, Ebensperger G, Llanos AJ, Reyes RV, González-Candia A and Herrera EA: Melatonin modulates the expression of pulmonary prostanoids. Rev Med Chil 147: 281-288, 2019 (In Spanish).

37. Wu X, Ji H, Wang Y, Gu C, Gu W, Hu L and Zhu L: Melatonin Alleviates Radiation-Induced Lung Injury via Regulation of miR-30e/NLRP3 Axis. Oxid Med Cell Longev 2019: 4087298, 2019.

38. Pourhanifeh MH, Sharifi M, Reiter RJ, Davoodabadi A and Asemi Z: Melatonin and non-small cell lung cancer: New insights into signaling pathways. Cancer Cell Int 19: 131, 2019.

39. Panmanee J, Nopparat C, Chavanich N, Shukla M, Mukda S, Song W, Vincent B and Govitrapong P: Melatonin regulates the transcription of $\beta$ APP-cleaving secretases mediated through melatonin receptors in human neuroblastoma SH-SY5Y cells. J Pineal Res 59: 308-320, 2015.

40. Hardeland R: Aging, Melatonin, and the Pro-and Anti-Inflammatory Networks. Int J Mol Sci 20: E1223, 2019.

41. Wang M-L, Wei C-H, Wang W-D, Wang J-S, Zhang J and Wang J-J: Melatonin attenuates lung ischaemia-reperfusion injury via inhibition of oxidative stress and inflammation. Interact Cardiovasc Thorac Surg 26: 761-767, 2018.

42. Sánchez A, Calpena AC and Clares B: Evaluating the Oxidative Stress in Inflammation: Role of Melatonin. Int J Mol Sci 16 16981-17004, 2015

43. Carrascal L, Nunez-Abades P, Ayala A and Cano M: Role of Melatonin in the Inflammatory Process and its Therapeutic Potential. Curr Pharm Des 24: 1563-1588, 2018.

44. Mańka S and Majewska E: Immunoregulatory action of melatonin. The mechanism of action and the effect on inflammatory cells. Postepy Hig Med Dosw 70: 1059-1067, 2016.

45. Dong Y-J, Ding C-H, Zhang Z, Gu W-W and Ma Y-L: Protective effects of melatonin in acute lung injury rats caused by LPS Zhongguo Ying Yong Sheng Li Xue Za Zhi 26: 481-484, 2010 (In Chinese)

46. Chiu M-H, Su C-L, Chen C-F, Chen K-H, Wang D and Wang J-J: Protective effect of melatonin on liver ischemia-reperfusion induced pulmonary microvascular injury in rats. Transplant Proc 44: 962-965, 2012

47. Reiter RJ, Rosales-Corral S, Tan DX, Jou MJ, Galano A and $\mathrm{Xu}$ B: Melatonin as a mitochondria-targeted antioxidant: One of evolution's best ideas. Cell Mol Life Sci 74: 3863-3881, 2017.

48. Bhattacharya S, Patel KK, Dehari D, Agrawal AK and Singh S Melatonin and its ubiquitous anticancer effects. Mol Cell Biochem 462: 133-155, 2019.

49. Tan D-X, Reiter RJ, Manchester LC, Yan MT, El-Sawi M, Sainz RM, Mayo JC, Kohen R, Allegra M and Hardeland R: Chemical and physical properties and potential mechanisms: Melatonin as a broad spectrum antioxidant and free radical scavenger. Curr Top Med Chem 2: 181-197, 2002

50. Poeggeler B, Thuermann S, Dose A, Schoenke M, Burkhardt S and Hardeland R: Melatonin's unique radical scavenging properties - roles of its functional substituents as revealed by a comparison with its structural analogs. J Pineal Res 33: 20-30, 2002.

51. Zheng X, Zhou J, Tan D-X, Wang N, Wang L, Shan D and Kong J: Melatonin Improves Waterlogging Tolerance of Malus baccata (Linn.) Borkh. Seedlings by Maintaining Aerobic Respiration, Photosynthesis and ROS Migration. Front Plant Sci 8: 483, 2017.

52. Yildiz A, Vardi N, Karaaslan MG, Ates B, Taslidere E and Esrefoglu M: The protective effect of melatonin in lungs of newborn rats exposed to maternal nicotine. Biotech Histochem 93: 442-452, 2018. 
53. Reiter RJ, Mayo JC, Tan D-X, Sainz RM, Alatorre-Jimenez M and Qin L: Melatonin as an antioxidant: Under promises but over delivers. J Pineal Res 61: 253-278, 2016.

54. Charão MF, Goethel G, Brucker N, Paese K, Eifler-Lima VL, Pohlmann AR, Guterres SS and Garcia SC: Melatonin-loaded lipid-core nanocapsules protect against lipid peroxidation caused by paraquat through increased SOD expression in Caenorhabditis elegans. BMC Pharmacol Toxicol 20 (Suppl 1): 80, 2019.

55. Radovic M, Ristic L, Krtinic D, Rancic M, Nickovic V, Vujnovic Zivkovic ZN, Zivkovic JB, Mirkovic MV, Toskic DR and Sokolovic D: Melatonin treatment prevents carbon tetrachloride-induced acute lung injury in rats by mitigating tissue antioxidant capacity and inflammatory response. Bratisl Lek Listy 120: 527-531, 2019.

56. Chen W, Chen X, Chen AC, Shi Q, Pan G, Pei M, Yang H, Liu T and He F: Melatonin restores the osteoporosis-impaired osteogenic potential of bone marrow mesenchymal stem cells by preserving SIRT1-mediated intracellular antioxidant properties. Free Radic Biol Med 146: 92-106, 2020.

57. de Matos Cavalcante AG, de Bruin PFC, de Bruin VMS, Nunes DM, Pereira EDB, Cavalcante MM and Andrade GM: Melatonin reduces lung oxidative stress in patients with chronic obstructive pulmonary disease: A randomized, double-blind, placebo-controlled study. J Pineal Res 53: 238-244, 2012.

58. Chen D, Zhang T and Lee TH: Cellular Mechanisms of Melatonin: Insight from Neurodegenerative Diseases. Biomolecules 10: E1158, 2020

59. Ostadmohammadi V, Soleimani A, Bahmani F, Aghadavod E, Ramezani R, Reiter RJ, Mansournia MA, Banikazemi Z, Soleimani M, Zaroudi M, et al: The Effects of Melatonin Supplementation on Parameters of Mental Health, Glycemic Control, Markers of Cardiometabolic Risk, and Oxidative Stress in Diabetic Hemodialysis Patients: A Randomized, Double-Blind, Placebo-Controlled Trial. J Ren Nutr 30 242-250, 2020.

60. Carlomagno G, Minini M, Tilotta M and Unfer V: From Implantation to Birth: Insight into Molecular Melatonin Functions. Int J Mol Sci 19: E2802, 2018.

61. Tan D-X, Hardeland R, Manchester LC, Galano A and Reiter RJ: Cyclic-3-hydroxymelatonin (C3HOM), a potent antioxidant, scavenges free radicals and suppresses oxidative reactions. Curr Med Chem 21: 1557-1565, 2014.

62. Fang Y, Zhang J, Li Y, Guo X, Li J, Zhong R and Zhang X Melatonin-induced demethylation of antioxidant genes increases antioxidant capacity through ROR $\alpha$ in cumulus cells of prepubertal lambs. Free Radic Biol Med 131: 173-183, 2019.

63. Esteban MÁ, Cuesta A, Chaves-Pozo E and Meseguer J: Influence of melatonin on the immune system of fish: A review. Int J Mol Sci 14: 7979-7999, 2013.

64. Carrillo-Vico A, Guerrero JM, Lardone PJ and Reiter RJ: A review of the multiple actions of melatonin on the immune system. Endocrine 27: 189-200, 2005.

65. Lee J, Byun H, Madhurakkat Perikamana SK, Lee S and Shin H: Current Advances in Immunomodulatory Biomaterials for Bone Regeneration. Adv Healthc Mater 8: e1801106, 2019. Zhang R, Wang X, Ni L, Di X, Ma B, Niu S, Liu C and Reiter RJ: COVID-19: Melatonin as a potential adjuvant treatment. Life Sci 250: 117583, 2020.

66. Channappanavar R and Perlman S: Pathogenic human coronavirus infections: Causes and consequences of cytokine storm and immunopathology. Semin Immunopathol 39: 529-539, 2017.

67. Haldar C and Ahmad R: Photoimmunomodulation and melatonin. J Photochem Photobiol B 98: 107-117, 2010.

68. Wu X, Ji H, Wang Y, Gu C, Gu W, Hu L and Zhu L: Melatonin Alleviates Radiation-Induced Lung Injury via Regulation of miR-30e/NLRP3 Axis. Oxid Med Cell Longev 2019: 4087298 , 2019.

69. Miller SC, Pandi-Perumal SR, Esquifino AI, Cardinali DP and Maestroni GJM: The role of melatonin in immuno-enhancement: Potential application in cancer. Int J Exp Pathol 87: 81-87, 2006.

70. Butt Y, Kurdowska A and Allen TC: Acute Lung Injury: A Clinical and Molecular Review. Arch Pathol Lab Med 140: 345-350, 2016

71. Morales-Ortíz J, Deal V, Reyes F, Maldonado-Martínez G, Ledesma N, Staback F, Croft C, Pacheco A, Ortiz-Zuazaga H, Yost CC, et al: Platelet-derived TLT-1 is a prognostic indicator in ALI/ARDS and prevents tissue damage in the lungs in a mouse model. Blood 132: 2495-2505, 2018
72. Bellani G, Laffey JG, Pham T, Fan E, Brochard L, Esteban A Gattinoni L, van Haren F, Larsson A, McAuley DF, et al; LUNG SAFE Investigators; ESICM Trials Group: Epidemiology, Patterns of Care, and Mortality for Patients With Acute Respiratory Distress Syndrome in Intensive Care Units in 50 Countries. JAMA 315: 788-800, 2016.

73. Rubenfeld GD, Caldwell E, Peabody E, Weaver J, Martin DP, Neff M, Stern EJ and Hudson LD: Incidence and outcomes of acute lung injury. N Engl J Med 353: 1685-1693, 2005.

74. Ranieri VM, Rubenfeld GD, Thompson BT, Ferguson ND, Caldwell E, Fan E, Camporota L and Slutsky AS; ARDS Definition Task Force: Acute respiratory distress syndrome: The Berlin Definition. JAMA 307: 2526-2533, 2012.

75. Ozdinc S, Oz G, Ozdemir C, Kilic I, Karakaya Z, Bal A, Koken T and Solak O: Melatonin: Is it an effective antioxidant for pulmonary contusion? J Surg Res 204: 445-451, 2016.

76. Zhang Z, Gao L, Ding C-H, Ma W-Z, Gu W-W and Ma Y-L: Protective function of melatonin to acute lung injury and its mechanisms in rats caused by oleic acid. Zhongguo Ying Yong Sheng Li Xue Za Zhi 27: 480-483, 2011 (In Chinese).

77. Taslidere E, Esrefoglu M, Elbe H, Cetin A and Ates B: Protective effects of melatonin and quercetin on experimental lung injury induced by carbon tetrachloride in rats. Exp Lung Res 40: 59-65, 2014.

78. Wu WS, Chou MT, Chao CM, Chang CK, Lin MT and Chang CP: Melatonin reduces acute lung inflammation, edema, and hemorrhage in heatstroke rats. Acta Pharmacol Sin 33: 775-782, 2012.

79. Huai J-P, Sun X-C, Chen M-J, Jin Y, Ye X-H, Wu J-S and Huang Z-M: Melatonin attenuates acute pancreatitis-associated lung injury in rats by modulating interleukin 22 . World $\mathrm{J}$ Gastroenterol 18: 5122-5128, 2012.

80. Zhang XH, Qi HX, Xu DS, Pang XC, Wang CY and Yu WJ: Expression of proteinase-activated receptor-2 and transient receptor potential A1 in vagal afferent nerve of rat after lung schemia-reperfusion injury. J Biol Regul Homeost Agents 33: 1405-1413, 2019

81. Fındık O, Yılmaz MY, Yazır Y, Rençber SF, Sarıhan KK and Kunt AT: Investigation of the protective effect of enoxaparin and ticagrelor pretreatment against ischemia-reperfusion injury in rat lung tissue. Rev Assoc Med Bras (1992) 65: 1193-1200, 2019.

82. Esteban-Zubero E, García-Gil FA, López-Pingarrón L, Alatorre-Jiménez MA, Iñigo-Gil P, Tan D-X, García JJ and Reiter RJ: Potential benefits of melatonin in organ transplantation: A review. J Endocrinol 229: R129-R146, 2016.

83. Banaei S, Ahmadiasl N and Alihemmati A: Comparison of the Protective Effects of Erythropoietin and Melatonin on Renal Ischemia-Reperfusion Injury. Trauma Mon 21: e23005, 2016.

84. Takhtfooladi H, Takhtfooladi M, Moayer F and Mobarakeh S: Melatonin attenuates lung injury in a hind limb ischemia-reperfusion rat model. Rev Port Pneumol 21: 30-35, 2015.

85. Lambrecht $\mathrm{BN}$ and Hammad $\mathrm{H}$ : The airway epithelium in asthma. Nat Med 18: 684-692, 2012.

86. Ryzhov S, Goldstein AE, Matafonov A, Zeng D, Biaggioni I and Feoktistov I: Adenosine-activated mast cells induce IgE synthesis by B lymphocytes: An A2B-mediated process involving Th2 cytokines IL-4 and IL-13 with implications for asthma. J Immunol 172: 7726-7733, 2004.

87. Steurer-Stey C: Asthmamanagement: Uberblick und neue Aspekte. Praxis (Bern 1994) 96: 1951-1957, 2007 (In German).

88. Woodruff Pg, Modrek B, Choy DF, Jia g, Abbas AR, Ellwanger A, Koth LL, Arron JR and Fahy JV: T-helper Type 2-driven Inflammation Defines Major Subphenotypes of Asthma. Am J Respir Crit Care Med 180: 388-395, 2009.

89. Brown V and Ennis M: T Cell Cytokine Production in Childhood Asthma. CRMR 1: 1-6, 2005.

90. Huang W-C, Liu C-Y, Shen S-C, Chen L-C, Yeh K-W, Liu S-H and Liou C-J: Protective Effects of Licochalcone A Improve Airway Hyper-Responsiveness and Oxidative Stress in a Mouse Model of Asthma. Cells 8: E617, 2019.

91. Cobham VE, Hickling A, Kimball H, Thomas HJ, Scott JG and Middeldorp CM: Systematic Review: Anxiety in Children and Adolescents With Chronic Medical Conditions. J Am Acad Child Adolesc Psychiatry 59: 59: 595-618, 2019.

92. To T, Stanojevic S, Moores G, Gershon AS, Bateman ED, Cruz AA and Boulet L-P: Global asthma prevalence in adults: Findings from the cross-sectional world health survey. BMC Public Health 12: 204, 2012. 
93. Wang YT, Chen SL and Xu SY: Effect of melatonin on the expression of nuclear factor-kappa B and airway inflammation in asthmatic rats. Zhonghua Er Ke Za Zhi 42: 94-97, 2004 (In Chinese).

94. Wu H-M, Shen Q-Y, Fang L, Zhang S-H, Shen P-T, Liu Y-J and Liu R-Y: JNK-TLR9 signal pathway mediates allergic airway inflammation through suppressing melatonin biosynthesis. J Pineal Res 60: 415-423, 2016.

95. Shin I-S, Park J-W, Shin N-R, Jeon C-M, Kwon O-K, Kim J-S, Kim J-C, Oh S-R and Ahn K-S: Melatonin reduces airway inflammation in ovalbumin-induced asthma. Immunobiology 219 901-908, 2014.

96. Shin I-S, Park J-W, Shin N-R, Jeon C-M, Kwon O-K, Lee M-Y, Kim H-S, Kim J-C, Oh S-R and Ahn K-S: Melatonin inhibits MUC5AC production via suppression of MAPK signaling in human airway epithelial cells. J Pineal Res 56: 398-407, 2014.

97. American Thoracic Society: Standardization of Spirometry, 1994 Update. Am J Respir Crit Care Med 152: 1107-1136, 1995.

98. Campos FL, da Silva-Júnior FP, de Bruin VM and de Bruin PF: Melatonin improves sleep in asthma: A randomized, double-blind, placebo-controlled study. Am J Respir Crit Care Med 170: 947-951, 2004.

99. Li Q, Qu HJ, Lv D, Yeh M-K, Sun S, Li L and Liao Y: Drug-related problems among hospitalized patients with COPD in mainland China. Int J Clin Pharm 41: 1507-1515, 2019.

100. Kc R, Shukla SD, Gautam SS, Hansbro PM and O'Toole RF: The role of environmental exposure to non-cigarette smoke in lung disease. Clin Transl Med 7: 39, 2018.

101. Brandsma CA, Van den Berge M, Hackett TL, Brusselle G and Timens W: Recent advances in chronic obstructive pulmonary disease pathogenesis: From disease mechanisms to precision medicine. J Pathol 250: 624-635, 2020

102. He B, Zhang W, Qiao J, Peng Z and Chai X: Melatonin protects against COPD by attenuating apoptosis and endoplasmic reticulum stress via upregulating SIRT1 expression in rats. Can J Physiol Pharmacol 97: 386-391, 2019.

103. Shin N-R, Ko J-W, Kim J-C, Park G, Kim S-H, Kim M-S, Kim J-S and Shin I-S: Role of melatonin as an SIRT1 enhancer in chronic obstructive pulmonary disease induced by cigarette smoke. J Cell Mol Med 24: 1151-1156, 2020.

104. Cherpanath TGV, Smeding L, Hirsch A, Lagrand WK, Schultz MJ and Groeneveld ABJ: Low tidal volume ventilation ameliorates left ventricular dysfunction in mechanically ventilated rats following LPS-induced lung injury. BMC Anesthesiol 15: 140, 2015.
105.Pandita A, Murki S, Oleti TP, Tandur B, Kiran S, Narkhede S and Prajapati A: Effect of Nasal Continuous Positive Airway Pressure on Infants With Meconium Aspiration Syndrome: A Randomized Clinical Trial. JAMA Pediatr 172: 161-165, 2018.

106. Sutherasan Y, Vargas M and Pelosi P: Protective mechanical ventilation in the non-injured lung: Review and meta-analysis. Crit Care 18: 211, 2014

107. Ball L, Hemmes SNT, Serpa Neto A, Bluth T, Canet J, Hiesmayr M, Hollmann MW, Mills GH, Vidal Melo MF, Putensen $\mathrm{C}$, et al; LAS VEGAS investigators; PROVE Network; Clinical Trial Network of the European Society of Anaesthesiology: Intraoperative ventilation settings and their associations with postoperative pulmonary complications in obese patients. Br J Anaesth 121: 899-908, 2018.

108. Yu Q, Wang D, Wen X, Tang X, Qi D, He J, Zhao Y, Deng W and Zhu T: Adipose-derived exosomes protect the pulmonary endothelial barrier in ventilator-induced lung injury by inhibiting the TRPV4/Ca ${ }^{2+}$ signaling pathway. Am J Physiol Lung Cell Mol Physiol 318: L723-L741, 2020.

109. van der Zee P and Gommers D: Recruitment Maneuvers and Higher PEEP, the So-Called Open Lung Concept, in Patients with ARDS. Crit Care 23: 73, 2019.

110. Alkasalias T, Alexeyenko A, Hennig K, Danielsson F, Lebbink RJ, Fielden M, Turunen SP, Lehti K, Kashuba V, Madapura HS, et al: RhoA knockout fibroblasts lose tumor-inhibitory capacity in vitro and promote tumor growth in vivo. Proc Natl Acad Sci USA 114: E1413-E1421, 2017.

111. Sripathi SR, Prigge CL, Elledge B, He W, Offor J, Gutsaeva DR and Jahng WJ: Melatonin Modulates Prohibitin and Cytoskeleton in the Retinal Pigment Epithelium. Int J Sci Eng Res 8: 502-506, 2017.

112. Gu C, Liu M, Zhao T, Wang D and Wang Y: Protective role of p120-catenin in maintaining the integrity of adherens and tight junctions in ventilator-induced lung injury. Respir Res 16: 58, 2015.

113. Ito K, Colley T and Mercado N: Geroprotectors as a novel therapeutic strategy for COPD, an accelerating aging disease. Int J Chron Obstruct Pulmon Dis 7: 641-652, 2012.

114. Giamarellos-Bourboulis EJ,Netea MG, Rovina N, Akinosoglou K, Antoniadou A, Antonakos N, Damoraki G, Gkavogianni T, Adami M-E, Katsaounou P, et al: Complex Immune Dysregulation in COVID-19 Patients with Severe Respiratory Failure. Cell Host Microbe 27: 992-1000.e3, 2020. 